\title{
Erratum: Attenuation measurements show that the presence of a TachoSil surgical patch will not compromise target irradiation in intra-operative electron radiation therapy or high-dose-rate brachytherapy
}

Sandra Sarmento ${ }^{1,2^{*}}$, Filipa Costa ${ }^{2}$, Alexandre Pereira ${ }^{1,2}$, Joana Lencart ${ }^{1,2}$, Anabela Dias ${ }^{1,2}$, Luís Cunha ${ }^{1,2}$, Olga Sousa ${ }^{3}$, José Pedro Silva ${ }^{4}$ and Lúcio Santos ${ }^{4,5}$

After publication of this study [1], the authors noticed that the funding was incorrectly acknowledged. The correct Acknowledgements section can be found below:

"This work was partly funded by Fundação para a Ciência e Tecnologia (FCT), in the framework of the project PTDC/SAU-ENB/117631/2010, which is cofinanced by FEDER, through Programa Operacional Fatores de Competitividade - COMPETE of QREN (reference FCOMP-01-0124-FEDER-021141)."

\section{Author details \\ 'Medical Physics Department, Portuquese Institute of Oncology, Porto, Portugal. ${ }^{2}$ Medical Physics, Radiobiology and Radiation Protection Group, Research Centre, Portuguese Institute of Oncology, Porto, Portugal. ${ }^{3}$ Radiation Oncology Department, Portuguese Institute of Oncology, Porto, Portugal. ${ }^{4}$ Surgical Oncology Department, Portuguese Institute of Oncology, Porto, Portugal. ${ }^{5}$ Experimental Pathology and Therapeutics Group, Research Centre, Portuguese Institute of Oncology, Porto, Portugal.}

Received: 29 November 2015 Accepted: 9 December 2015

Published online: 15 December 2015

\section{Reference}

1. Sarmento S, Costa F, Pereira A, Lencart J, Dias A, Cunha L, et al. Attenuation measurements show that the presence of a TachoSil surgical patch will not compromise target irradiation in intra-operative electron radiation therapy or high-dose-rate brachytherapy. Radiat Oncol. 2015;10:07.

\footnotetext{
* Correspondence: ssarment@gmail.com

${ }^{1}$ Medical Physics Department, Portuguese Institute of Oncology, Porto, Portugal

${ }^{2}$ Medical Physics, Radiobiology and Radiation Protection Group, Research Centre, Portuguese Institute of Oncology, Porto, Portugal
}

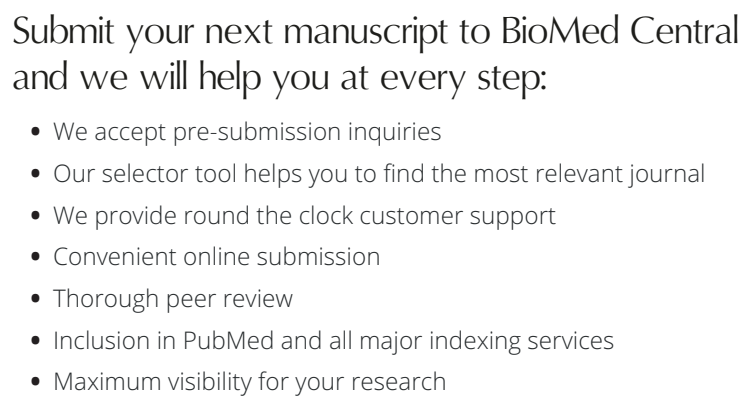

Submit your next manuscript to BioMed Central and we will help you at every step:

- We accept pre-submission inquiries

- Our selector tool helps you to find the most relevant journal

- We provide round the clock customer support

- Convenient online submission

- Thorough peer review

- Inclusion in PubMed and all major indexing services

- Maximum visibility for your research

Submit your manuscript at

www.biomedcentral.com/submit 